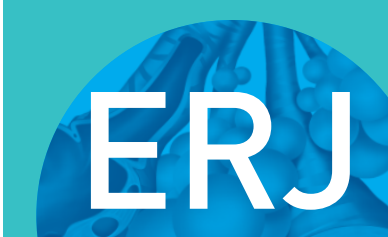

open research

\title{
Incidence of primary spontaneous pneumothorax: a validated, register-based nationwide study
}

\author{
Winnie Hedevang Olesen ${ }^{1}$, Ingrid Louise Titlestad ${ }^{2}$, Poul Erik Andersen ${ }^{3}$, \\ Rune Lindahl-Jacobsen ${ }^{4,5}$ and Peter Bjørn Licht ${ }^{1}$
}

Affiliations: ${ }^{1}$ Dept of Cardiothoracic Surgery, Odense University Hospital, Odense, Denmark. ${ }^{2}$ Dept of Respiratory Medicine, Odense University Hospital, Odense, Denmark. ${ }^{3}$ Dept of Radiology, Odense University Hospital, Odense, Denmark. ${ }^{4}$ Danish Aging Research Center, Unit of Epidemiology, Biostatistics and Biodemography, University of Southern Denmark, Odense, Denmark. ${ }^{5}$ Max Planck Odense Center on Biodemography of Aging, Odense, Denmark.

Correspondence: Winnie Hedevang Olesen, Dept of Cardiothoracic Surgery, Odense University Hospital, 29 Sdr. Boulevard, Odense DK-5000, Denmark. E-mail: winnie.olesendrsyd.dk

\section{ABSTRACT}

Objectives: The incidence of primary spontaneous pneumothorax is partly unknown. Commonly quoted estimates were published decades ago and recent large-scale epidemiological publications lack validation. We validated the pneumothorax diagnosis in a national registry and estimated the incidence of primary spontaneous pneumothorax in young patients.

Methods: Complete data on patients with an assigned pneumothorax diagnosis was retrieved from the National Danish Patient Registry. Initially, we validated the diagnosis in a selected population: all patient charts with an assigned pneumothorax diagnosis from one cardiothoracic department over a 25-year period (1984-2008) were reviewed. Subsequently, the national incidence of primary spontaneous pneumothorax in young, healthy individuals was estimated by restricting our population to patients $\leqslant 40$ years of age admitted during a 5-year period (2009-2014). We performed a systematic read-though of patient charts in $50 \%$ of the complete national cohort to ensure that we only included patients with their first episode of primary spontaneous pneumothorax.

Results: Validation revealed a poor inter-rater agreement $(\kappa=0.08)$. Therefore, we abstained from further analysis on directly retrieved data from the national database. Subsequently, a systematic re-evaluation of 7022 patients revealed an incidence rate of 12.3 cases per 100000 (95\% CI 11.5-13.1) in males and 2.2 cases per 100000 (95\% CI 1.9-2.6) in females (male/female ratio 5.9). Compared with the general Danish population, pneumothorax patients had a lower body mass index $(\mathrm{p}<0.001)$ and smoked more than the Danish population in general $(\mathrm{p}<0.001)$.

Conclusions: The incidence of primary spontaneous pneumothorax in a validated national study was lower than previously reported.

@ERSpublications

The overall incidence of primary spontaneous pneumothorax was much lower in a validated, register-based nationwide study than previously reported. There were large sex-related differences and a confirmed, strong male predominance http://ow.ly/Uxjp30ob9Fz

Cite this article as: Olesen WH, Titlestad IL, Andersen PE, et al. Incidence of primary spontaneous pneumothorax: a validated, register-based nationwide study. ERJ Open Res 2019; 5: 00022-2019 [https://doi.org/10.1183/23120541.00022-2019].

Received: Jan 232019 | Accepted after revision: March 092019

Copyright $\odot$ ERS 2019. This article is open access and distributed under the terms of the Creative Commons Attribution Non-Commercial Licence 4.0. 


\section{Introduction}

Primary spontaneous pneumothorax (PSP) conventionally refers to patients with no obvious precipitating factor, while those with an established lung pathology are classified as secondary pneumothorax (SSP) $[1,2]$. Commonly quoted estimates of incidence of spontaneous pneumothorax are based on older studies and restricted to single-centre samples [3,4]. Only two large epidemiological studies from the UK [5] and France [6] have been published, and these were both limited by lack of external validation of the databases $[5,6]$. Furthermore, when the present International Classification of Diseases (ICD) is applied to an existing database, it is not possible to differentiate between PSP and SSP. Hence, in previous publications, differentiation between the two forms of spontaneous pneumothorax relied solely on the age of the patient [5] or applied diagnosis of comorbidities [6] from the treating physician, and the validity of these databases remains uncertain.

The aim of this study was to validate pneumothorax diagnosis in a national registry and subsequently estimate the true national incidence rate of the first occurrence of PSP in otherwise healthy, young adults in Denmark.

\section{Materials and methods}

The present study was approved by the Regional Ethics Committee of Southern Denmark (project ID S-20090052) and the Danish Data Protection Agency. The study was conducted in accordance with the Declaration of Helsinki.

The healthcare system in Denmark is public and free for all citizens. The diagnosis and treatment of pneumothorax is limited to this public system. The present study is based on data from the Danish National Patient Registry (DNPR) database, which collects nationwide data on all contacts with the Danish healthcare system including hospital stays, emergency room contacts and visits to outpatient clinics $[7,8]$. The purpose of the database is primarily administrative (monitoring of hospital activity based on the diagnostic-related groups (DRGs) model). Data are collected in real time and frequently analysed. Diagnostic coding relies on the World Health Organization ICD and follows it updates. The main diagnosis, as well as comorbidities, is allocated by the treating physician immediately after discharge.

Since 2009, all patient charts in Denmark have been directly available online in the Danish national electronic patient register. By use of the unique personal registration number given to all Danes at birth [9-11], the complete chart of any patient can be accessed online including all hospital admissions and visits to outpatient clinics or emergency rooms, dating back to the year 2000. In many parts of our country, older patient charts are also available electronically.

We intended to estimate the national incidence rate of PSP by using data form the DNPR. First, we retrieved exhaustive data from the DNPR over a 30-year period (1984-2014) of all patients with a pneumothorax diagnosis, according to the ICD system and/or known insertion of a chest tube according to the DRG system. Then, we validated the DNPR using a selected population as described in detail later. Finally, as this validation revealed low agreement, we abstained from further analysis relying solely on the retrieved data from DNPR. Instead, we performed a thorough review of all patient charts in the Danish national electronic file system to identify those patients who experienced their first episode of PSP over a 5 -year period and calculated the national incidence of PSP in Denmark.

\section{Validation population}

We selected all patients admitted to one of the four national cardiothoracic centres (Odense University Hospital, Odense, Denmark) with a diagnosis of pneumothorax according to the ICD system over a 25-year period (January 1, 1984 to December 31, 2008). This cardiothoracic department was chosen because all historic patient charts were accessible. Our search was limited to patients older than 15 years because younger patients were admitted to the paediatric department. Every patient chart was systematically investigated, and the original diagnosis applied by the treating physician immediately after discharge was recorded and compared with the diagnosis we estimated to be appropriate after reviewing the patient charts. We assigned diagnoses as described in detail in table 1 and compared the originally assigned diagnosis to the applied diagnosis after re-evaluation by $\kappa$-statistics.

\section{The Danish national cohort}

To estimate the national incidence rate of PSP in young, healthy patients, we restricted our search to pneumothorax patients who were $\leqslant 40$ years old and were admitted to the hospital within a 5-year period (June 1, 2009 to May 31, 2014). The goal was to identify all consecutive patients admitted with their first episode of PSP, verified by a chest radiography on admission, in Denmark. Patients with recurrent pneumothorax and SSP were not included in this study. Likewise, patients older than 40 years of age were excluded to avoid bias from unacknowledged underlying comorbidity. After identifying the complete 


\section{TABLE 1 Explanation of how each diagnosis was assigned during the systematic read-through}

\begin{tabular}{|c|c|}
\hline Diagnosis & Criteria \\
\hline Spontaneous PTX & Occurring with no apparent cause with or without tension \\
\hline PSP & PSP: occurring in otherwise healthy individuals \\
\hline \multirow[t]{2}{*}{ SSP } & SSP: occurring in patients with pre-existing lung-disorder \\
\hline & $\begin{array}{l}\text { We assigned tension PTX diagnosis if there was evidence in the chart } \\
\text { both clinically and by chest radiography to support this diagnosis. }\end{array}$ \\
\hline Traumatic PTX & Occurring as a direct result of trauma, including haemothorax \\
\hline latrogenic PTX & $\begin{array}{l}\text { Occurring unintentionally as a direct result of treatment, examination or } \\
\text { surgery performed on the patient }\end{array}$ \\
\hline Perinatal/congenital PTX & $\begin{array}{l}\text { Occurring in relation to child birth or as a direct result of congenital } \\
\text { disorders }\end{array}$ \\
\hline $\begin{array}{l}\text { Isolated } \\
\text { pneumomediastinum }\end{array}$ & Typically occurring after extreme coughing or giving birth \\
\hline Thoracentesis & $\begin{array}{l}\text { Surgical puncture and drainage of the thoracic cavity, either diagnostic or as } \\
\text { treatment }\end{array}$ \\
\hline Empyema & A condition where pus collects in the pleural cavity \\
\hline Misclassification & $\begin{array}{l}\text { Suspected PTX; however, this was disproved but the diagnosis was } \\
\text { maintained and reported to the national database by mistake }\end{array}$ \\
\hline $\begin{array}{l}\text { No apparent reason for } \\
\text { PTX }\end{array}$ & $\begin{array}{l}\text { Patients where no apparent reason for their PTX diagnosis was identified, } \\
\text { despite thorough examination of all charts from the year } 2000 \text { onwards }\end{array}$ \\
\hline & Probably a PTX incident prior to the year 2000 or possibly misclassification \\
\hline
\end{tabular}

national cohort, we systematically reviewed all patient charts in $50 \%$ of the complete national cohort to identify the correct patients and avoid selection bias. Patients were selected by their date of birth beginning with all patients born the first of each month then all patients born on the second of each month and so on until $50 \%$ was reviewed.

We extracted information about sex, age at debut, affected lung and symptoms at onset. Whenever available, smoking habits and body mass index (BMI) were recorded. According to the Danish national guidelines, a patient was considered an ex-smoker if they stopped smoking $>6$ months ago [12]. Furthermore, information about treatment facility and modality as well as hospital duration was recorded. As we required $\geqslant 1$ year of follow-up, all charts were reviewed again and assessed for readmissions due to recurrent spontaneous pneumothorax in the spring of 2016.

To calculate an exact incidence rate, we retrieved information from Statistics Denmark on the population at risk, matched by sex and age, in each time interval [13].

\section{Statistical analysis}

Groups were compared by Chi-squares test for categorical data and by Mann-Whitney test for numerical data. The measure of agreement between two groups where calculated by $\kappa$-statistic. All incidence rates are presented with 95\% confidence intervals. All data were analyses using STATA (Release 13; StataCorp LP, College Station, TX, USA).

\section{Results}

Validation population

We identified 1632 consecutive patients admitted to the Dept of Cardiothoracic Surgery, Odense University Hospital with any type of pneumothorax diagnosis over a period of 25 years (1984-2008). The male/female ratio was 2.4. Table 2 displays the originally applied diagnosis and the diagnosis after re-evaluating each patient chart. The overall $\kappa$-value was 0.08 , corresponding to an agreement of $22 \%$, indicating poor inter-rater agreement. We only observed a very good inter-rater agreement (97\%) for "traumatic pneumothorax".

\section{The Danish national population}

We identified 14044 unique patients with a pneumothorax diagnosis and/or chest tube insertion from the DNPR. We systematically reviewed $50 \%$ of the patient charts from this cohort. A flowchart of the exact method of selection of eligible patients is displayed in figure 1. 


\section{TABLE 2 Pneumothorax (PTX) diagnoses in the validation population}

PTX diagnosis (ICD code)

ICD diagnosis applied originally

ICD diagnosis

\section{Spontaneous PTX}

With tension ( J93.0)

Without tension (J93.1) $\quad 491 \quad 666$

latrogenic PTX

$\begin{array}{lll}\text { Post-surgery ( J95.8A) } & 14 & 117\end{array}$

latrogenic (T81.2) $\quad 0 \quad 67$

Traumatic PTX (S.27.0) $\quad 476 \quad 490$

Other kinds of PTX ( J93.8) $15 \quad 0$

Unspecified PTX ( J93.9) 599

Misclassification

ICD: International Classification of Diseases.
14044 patients identified in DNPR with a pneumothorax diagnosis and/or chest tube insertion over 5 years in Denmark

$7022(50 \%)$ patients were excluded (latter half)

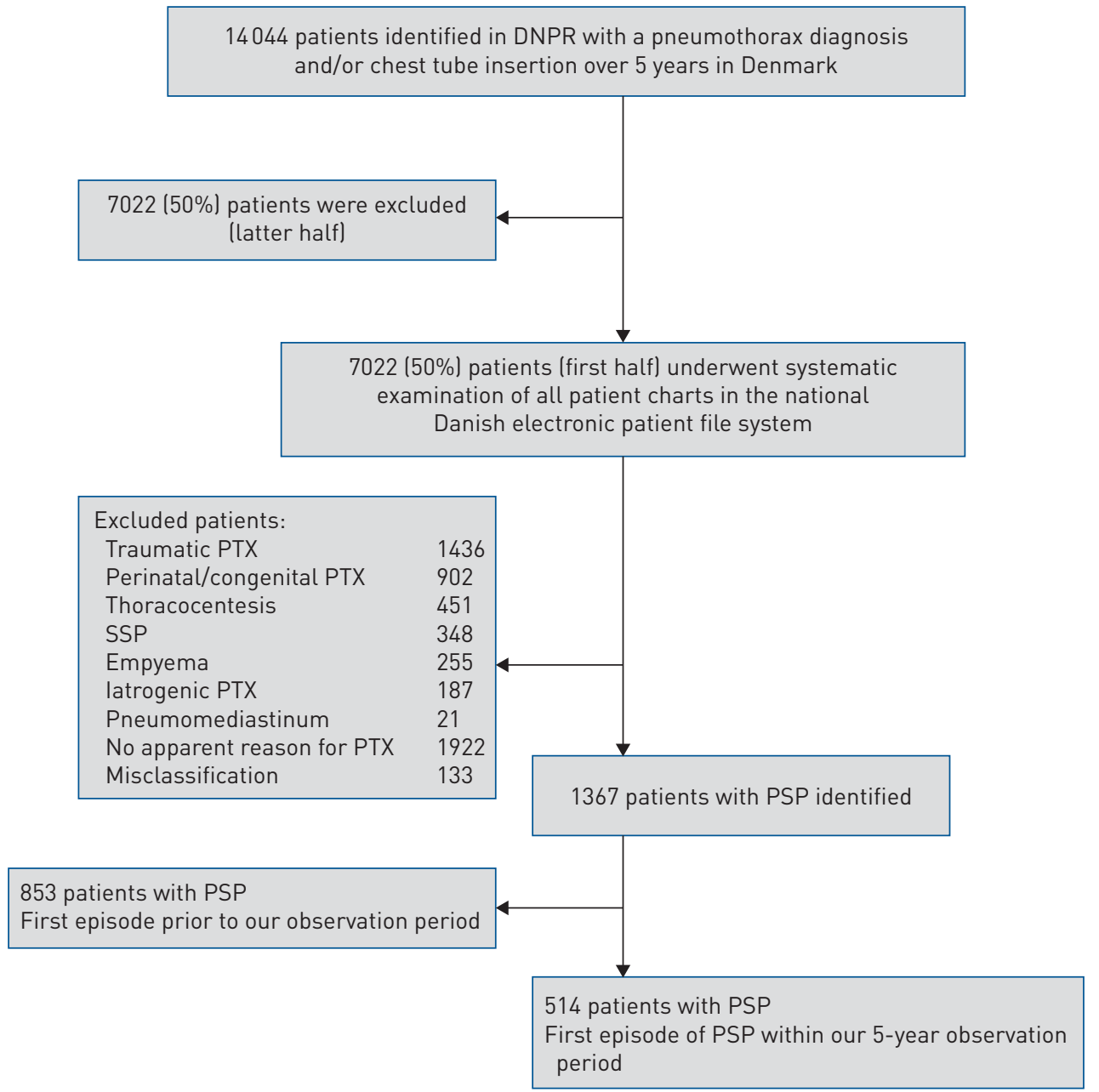

FIGURE 1 Flowchart showing the selection of primary spontaneous pneumothorax (PSP) patients in the national cohort. DNPR: Danish National Patient Registry; PTX: pneumothorax; SSP: secondary spontaneous pneumothorax. 


\begin{tabular}{|c|c|c|c|c|c|c|}
\hline \multirow[t]{2}{*}{ Variables } & \multicolumn{2}{|c|}{ Overall } & \multicolumn{2}{|c|}{ Female } & \multicolumn{2}{|r|}{ Male } \\
\hline & Patients & IR (95\% CI) & Patients & IR (95\% CI) & Patients & IR (95\% CI) \\
\hline \multicolumn{7}{|l|}{ Age group } \\
\hline $0-10$ years & 0 & 0 & 0 & 0 & 0 & 0 \\
\hline $11-15$ years & 36 & $2.1(1.5-2.9)$ & 2 & $0.2(0.1-0.8)$ & 34 & $3.9(2.8-5.5)$ \\
\hline $16-20$ years & 278 & $15.6(9.5-25.6)$ & 22 & $2.5(1.6-3.8)$ & 256 & $28.1(24.9-31.8)$ \\
\hline $21-25$ years & 242 & $14.2(8.4-23.9)$ & 28 & $3.3(2.3-4.8)$ & 214 & $24.7(21.6-28.2)$ \\
\hline $26-30$ years & 182 & 11.5 (6.5-20.5) & 28 & $3.6(2.5-5.2)$ & 154 & $19.3(16.5-22.6)$ \\
\hline $31-35$ years & 166 & $9.6(5.1-18.1)$ & 36 & $4.2(3.0-5.8)$ & 130 & $15.0(12.6-17.8)$ \\
\hline $36-40$ years & 124 & $6.5(3.0-14.0)$ & 34 & $3.5(2.5-4.9)$ & 90 & $9.3(7.6-11.4)$ \\
\hline Overall & 1028 & $7.3(6.9-7.8)$ & 150 & $2.2(1.9-2.6)$ & 878 & $12.3(11.5-13.1)$ \\
\hline \multicolumn{7}{|l|}{ Year } \\
\hline 2009-2010 & 168 & $6.0(5.2-6.9)$ & 26 & 1.9 (1.3-2.8) & 142 & 10.0 (8.5-11.8) \\
\hline $2010-2011$ & 196 & $7.0(6.1-8.1)$ & 20 & $1.4(0.9-2.2)$ & 176 & $12.3(10.6-14.3)$ \\
\hline 2011-2012 & 198 & $7.1(6.2-8.2)$ & 38 & $2.8(2.0-3.8)$ & 160 & $11.2(9.6-13.1)$ \\
\hline 2012-2013 & 248 & $8.7(7.7-9.6)$ & 26 & $1.9(1.3-2.8)$ & 222 & $15.6(13.7-17.8)$ \\
\hline 2013-2014 & 218 & $8.2(7.2-9.4)$ & 40 & $2.9(2.1-4.0)$ & 178 & $12.5(10.8-14.5)$ \\
\hline
\end{tabular}

After careful re-evaluation of the 7022 patient charts, we identified 514 patients with their first episode of PSP during the 5-year observation period, corresponding to a total of 1028 patients in the entire cohort or $\sim 205$ new patients per year in Denmark.

The national incidence rate of PSP was 7.3 (95\% CI 6.9-7.8) (table 3). The incidence rate differed significantly between the two sexes $(p<0.001)$. In females, the incidence rate was 2.2 cases per 100000 (95\% CI 1.9-2.6) and in males it was 12.3 cases per 100000 (95\% CI 11.5-13.1). Male patients had a peak in incidence at the age of 16-25 years (table 3 and figure 2). In contrast, the incidence rates in females were more uniform regarding age (table 3 and figure 2). There was no statistically significant change in incidence rate over time in either sex (table 3 and figure 3 ).

We observed an overall male/female ratio of 5.9. Baseline characteristics are presented in table 4, where it is seen that females had a significantly higher age at debut $(\mathrm{p}<0.01)$, while male patients smoked more $(\mathrm{p}=0.024)$. BMI $(\mathrm{p}=0.72)$ and the affected lung $(\mathrm{p}=0.29)$ did not differ significantly between the two sexes.

\section{The first admission}

The vast majority experienced a sudden onset of symptoms (95\%) and 75\% was admitted to the hospital within the first $24 \mathrm{~h}$ after onset (table 5). Commonly, the patient was either at rest (70\%) or sleeping (16\%). Rarely, the symptoms occurred in relation to physical exercise (table 5). In the majority of patients, treatment was completed on a general surgical or medical ward (64\%), but $36 \%$ was admitted directly or

FIGURE 2 Incidence rate (IR) per 100000 by age, overall and divided by sex.

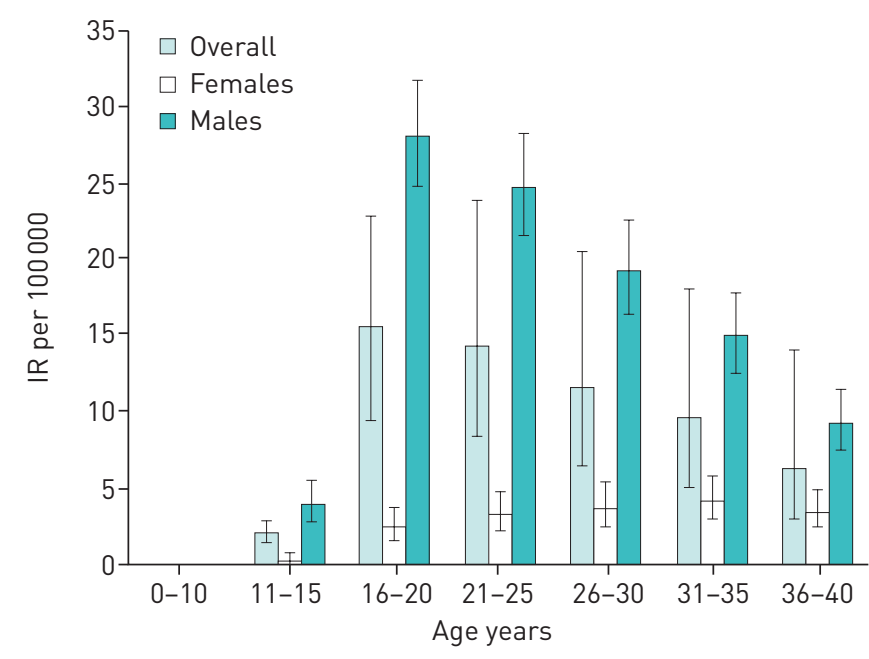


FIGURE 3 Incidence rate (IR) per 100000 per year, overall and divided by sex.

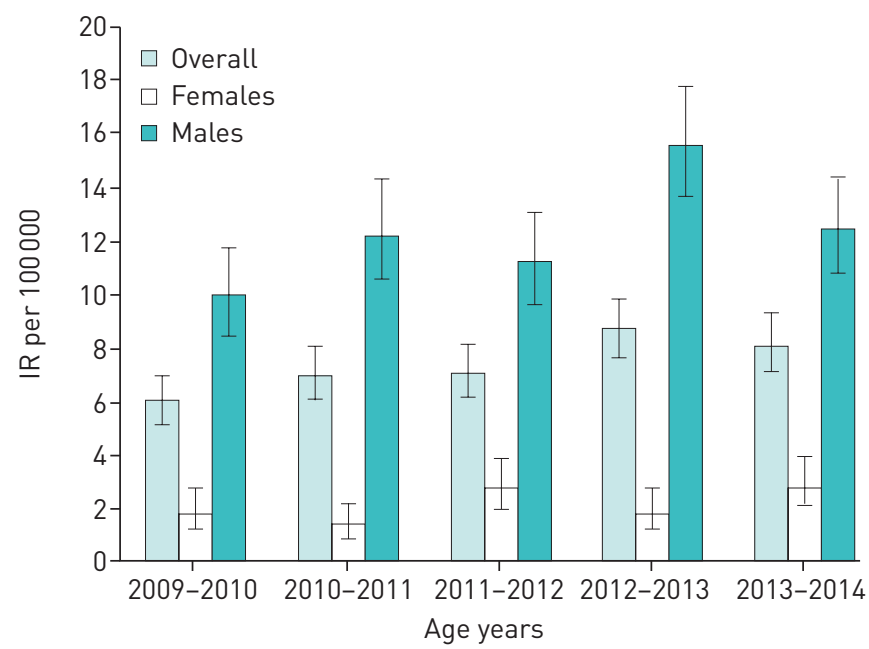

later referred to one of the four national cardiothoracic departments. The median hospitalisation duration was 4 days (range 1-30 days) and the majority (86\%) required insertion of a chest tube during hospitalisation. Surgical treatment was performed in $17.5 \%$ of the patients during their first admission (table 5) and more frequently in females than males $(\mathrm{p}<0.001)$. The 514 patients experienced a total of 1030 hospitalisations during the observation period. We observed all patients for $\geqslant 1$ year; the overall recurrence rate ipsilaterally following treatment with a chest tube and after primary preventive surgical intervention was $38 \%$ and $13 \%$ respectively. Females experienced a significantly higher ipsilateral recurrence rate than males following treatment with a chest tube: $48 \%$ and $37 \%$ in males and females respectively $(p=0.029)$. In contrast, we observed no difference in recurrence rate between the two sexes following primary preventive surgery $(p=0.83)$. Onset pattern $(p=0.16)$, treatment facility $(p=0.88)$, length of hospital stay $(\mathrm{p}=0.13)$ and initial treatment $(\mathrm{p}=0.85)$ did not differ significantly between the two sexes.

\section{Discussion}

The principal difference between the present and previous publications is the initial validation of our nationwide database followed by a systematic read-though of a large sample of the complete national cohort to ensure identification of the real PSP patients. In addition to identifying the individuals with PSP

\section{TABLE 4 Baseline characteristics of the 514 patients with primary spontaneous pneumothorax}

\begin{tabular}{|c|c|c|c|}
\hline Variable & Overall & Female & Male \\
\hline Patients & 514 & $75(15 \%)$ & $439(85 \%)$ \\
\hline \multicolumn{4}{|c|}{ Age on first admission years } \\
\hline Median (range) & $25(12-40)$ & $29(15-40)$ & $24(12-40)$ \\
\hline Mean $\pm S D$ & $25.7 \pm 7.1$ & $29.2 \pm 7.2$ & $25.1 \pm 6.9^{9}$ \\
\hline \multicolumn{4}{|l|}{ Lung affected initially } \\
\hline Right lung & $256(53 \%)$ & $36(48 \%)$ & $220(50 \%)$ \\
\hline Left lung & $254(46 \%)$ & $37(49 \%)$ & $217(49 \%)$ \\
\hline Bilateral & $4(1 \%)$ & $2(3 \%)$ & $2(1 \%)$ \\
\hline \multicolumn{4}{|c|}{ Body mass index $\mathrm{kg} \cdot \mathrm{m}^{-2}$} \\
\hline Median (range) & $20.4(12.7-33.2)$ & $20.4(12.7-33.2)$ & $20.4(13.9-29.2)$ \\
\hline Mean $\pm \mathrm{SD}^{\#}$ & $20.7 \pm 3.1$ & $20.9 \pm 4.5$ & $20.7 \pm 2.7$ \\
\hline \multicolumn{4}{|l|}{ Smoking habits } \\
\hline Never-smokers & $136(27 \%)$ & $22(29 \%)$ & $114(26 \%)$ \\
\hline Daily smokers & $299(58 \%)$ & $36(48 \%)$ & $263(60 \%)$ \\
\hline Weekly smokers & $12(2 \%)$ & 2 (3\%) & $10(2 \%)$ \\
\hline Less than weekly & $8(1.5 \%)$ & $3(4 \%)$ & $5(1 \%)$ \\
\hline Ex-smokers & $21(4 \%)$ & $8(10 \%)$ & $13(3 \%)$ \\
\hline Unknown & $36(7 \%)$ & $4(5 \%)$ & $32(7 \%)$ \\
\hline
\end{tabular}




\begin{tabular}{|c|c|c|c|}
\hline Variable & Overall & Female & Male \\
\hline Patients & 514 & $75(15 \%)$ & $439(85 \%)$ \\
\hline \multicolumn{4}{|l|}{ Characteristics at first onset } \\
\hline Sudden onset of symptoms & $490(95 \%)$ & $68(91 \%)$ & $422(96 \%)$ \\
\hline Admitted to hospital within $24 \mathrm{~h}$ after onset & $385(75 \%)$ & $46(61 \%)$ & $339(77 \%)$ \\
\hline \multicolumn{4}{|l|}{ Symptom onset during } \\
\hline Sleep & $82(16 \%)$ & $11(14 \%)$ & $71(16 \%)$ \\
\hline Rest & $359(70 \%)$ & $59(79 \%)$ & $300(68 \%)$ \\
\hline Normal activities of daily living & $56(11 \%)$ & $5(7 \%)$ & $51(12 \%)$ \\
\hline Exercise & $17(3 \%)$ & 0 & $17(4 \%)$ \\
\hline \multicolumn{4}{|l|}{ Treatment facility at first admittance } \\
\hline Cardiothoracic centre & $99(19 \%)$ & $14(19 \%)$ & $85(19 \%)$ \\
\hline General surgical/medical ward & $326(64 \%)$ & $45(60 \%)$ & $281(64 \%)$ \\
\hline Referred from general ward to cardiothoracic centre & $89(17 \%)$ & $16(21 \%)$ & $73(17 \%)$ \\
\hline \multicolumn{4}{|l|}{ Hospitalisation duration days } \\
\hline Median (range) & $4(1-30)$ & $4(1-20)$ & $4(1-30)$ \\
\hline Mean \pm SD & $5.1 \pm 4.27$ & $5.8 \pm 5.03$ & $5.0 \pm 4.11$ \\
\hline \multicolumn{4}{|l|}{ Treatment on first admission } \\
\hline \multicolumn{4}{|l|}{ Initial treatment } \\
\hline Observation & $74(14 \%)$ & $11(15 \%)$ & $63(14 \%)$ \\
\hline Chest tube with/without suction & $440(86 \%)$ & $64(85 \%)$ & $376(86 \%)$ \\
\hline \multicolumn{4}{|l|}{ Surgical treatment performed during the first admission } \\
\hline $\begin{array}{l}\text { VATS resection of blebs with partial pleurectomy or pleural } \\
\text { abrasion }\end{array}$ & $88(17 \%)$ & $21(28 \%)$ & $69(16 \%)$ \\
\hline Resection of bullae by thoracotomy & $2(0.5 \%)$ & 0 & $2(0.5 \%)$ \\
\hline
\end{tabular}

precisely, the advantage of direct access to all patient charts allowed us to gather valuable information about baseline characteristics including onset of symptoms, treatment and existing comorbidities.

Our nationwide database forms the cornerstone of many national epidemiological studies; surprisingly, we observed a poor inter-rater agreement. Often, the treating physician would assign the diagnosis "unspecified pneumothorax" (table 2), probably because it was easier. Such practice, however, leaves a considerable problem for research because it is impossible to differentiate PSP from other types of pneumothorax. Previous largescale epidemiological studies did not address this essential problem [5, 6].

We observed a national incidence rate of PSP of 7.3 per 100000 (table 3), which is much lower than previously reported. We also observed significant differences in incidence rate between the two sexes, where males had an approximately six times higher incidence rate than females (table 3). Previous publications from single-centre observations 45 years ago in the USA [3] and 30 years ago in Sweden [4] reported PSP incidence of 7.4-18 per 100000 and 1.2-6 per 100000 per annum in males and females respectively. More recently, two larger epidemiological studies from the UK [5] in the year 2000 and France [6] in 2015 indicated a rising tendency with a reported combined hospital admission rate for PSP and SSP of 16.7-22.7 per 100000 . These differences may of course be explained simply by variation in PSP over time but may also reflect the fact that we performed a systematic review and, hence, our estimate only reflects true PSP patients.

In the present study, males had a peak incidence at age 16-25 years (figure 2). This observation is in accordance with previous studies that also described a specific peak age in young males with PSP $[3,5,6]$.

The sex-related differences we observed once again raise the question of whether females actually suffer from an unacknowledged disease rather than PSP as their pattern of disease presented very different compared to males.

In accordance with previous observations [3-6], we confirmed a strong male predominance in PSP (male/ female ratio 5.9). Both lungs were affected equally on first admission. Height and weight were available in $225(44 \%)$ patients (table 4). Of these, $98(44 \%)$ patients were underweight, with a BMI $<18.6 \mathrm{~kg} \cdot \mathrm{m}^{-2}$, and only 31 (14\%) patients were overweight $\left(\mathrm{BMI}>25 \mathrm{~kg} \cdot \mathrm{m}^{-2}\right)$. Compared with the population in general patients with PSP had a significant lower weight $(\mathrm{p}<0.001)$ (table 4) [14]. In keeping with previous publications [4, 15-17], Danish PSP patients also smoked considerably more than the Danish population 
in general [14]. In the vast majority of patients (76\%), the onset of symptoms occurred while sleeping or resting (table 5). Only 3\% experienced onset while exercising. This is in accordance with previous findings [18] and underlines that PSP primarily occurs at rest or during effortless activity.

In the majority of our patients, treatment was completed on a general surgical/medical ward but $17 \%$ were referred to a cardiothoracic centre during their first admission, typically due to prolonged air leakage (table 5). The treatment of choice was insertion of a chest tube (86\%). We observed an overall ipsilateral recurrence rate of $38 \%$ following treatment with chest tube. Females experienced a significantly higher recurrence rate than males. This recurrence rate is in accordance with recent observations on the Danish population [19]. However, our observations regarding recurrence rate were in contrast with previous published epidemiological studies [3-6] but may be explained by the fact that our study focused on young, otherwise healthy individuals, and due to the systematic review, our cohort is restricted to PSP patients only. This considerable recurrence rate underlines the burden these patients put on the public healthcare system. Following surgery, the recurrence rate on the ipsilateral lung was significantly lowered but remained $13 \%$. This observation is in line with previous findings [20,21], highlighting that preventive surgery is no complete guarantee. New bullae may form over time and patients should be advised to seek medical attention if they experience similar symptoms even though they underwent preventive surgery previously. Table 5 shows that video-assisted thoracoscopic surgery (VATS) bullectomy, combined with either pleural abrasion or partial pleurectomy, was the surgical treatment of choice in Denmark. Although some publications indicate that recurrence rates may be lower $(0-7 \%)$ if surgery is performed through thoracotomy [20,22], VATS should represent the treatment of choice due to its minimal invasiveness and cosmetic advantage in a young population [23]

The strength of the present study is the validation of the existing nationwide database and the consequent systematic review of all available patient charts ensuring a high level of credibility to our dataset. As all pneumothorax patients are treated within the public system in Denmark, we had access to nationwide, exhaustive data, which should ensure a high accuracy of our estimated incidence rate. We chose to perform a systematic review of a large sample (50\%) of our national cohort to avoid selection bias and ensure a reasonable sample size for analysis. We have no reason to believe the remaining half of the national cohort differ in any way from the selected half.

In conclusion, our study confirmed that the typical PSP patient is a male smoker with low BMI. The national incidence rate in Denmark in young, otherwise healthy individuals is lower than previously reported, and we observed many differences between the two sexes.

\section{Conflict of interest: None declared.}

Support statement: This study was supported by The Danish Lung Association, The Beckett Foundation, The Danish Medical Association, The Research Council at Odense University Hospital and The Research Council of the Region of Southern Denmark. The funders of this study had no role in study design, data collection, data analysis, data interpretation or writing the report. Funding information for this article has been deposited with the Crossref Funder Registry.

\section{References}

1 Baumann MH. Management of spontaneous pneumothorax. Clin Chest Med 2006; 27: 369-381.

2 Henry M, Arnold T, Harvey J. BTS guidelines for the management of spontaneous pneumothorax. Thorax 2003; 58: Suppl. 2, ii39-ii52.

3 Melton LJ III, Hepper NG, Offord KP. Incidence of spontaneous pneumothorax in Olmsted County, Minnesota: 1950 to 1974. Am Rev Respir Dis 1979; 120: 1379-1382.

4 Bense L, Eklund G, Wiman LG. Smoking and the increased risk of contracting spontaneous pneumothorax. Chest 1987; 92: 1009-1012.

5 Gupta D, Hansell A, Nichols T, et al. Epidemiology of pneumothorax in England. Thorax 2000; 55: 666-671.

6 Bobbio A, Dechartres A, Bouam S, et al. Epidemiology of spontaneous pneumothorax: gender-related differences. Thorax 2015; 70: 653-658.

7 Erlangsen A, Fedyszyn I. Danish nationwide registers for public health and health-related research. Scand J Public Health 2015; 43: 333-339.

8 Thygesen LC, Daasnes C, Thaulow I, et al. Introduction to Danish (nationwide) registers on health and social issues: structure, access, legislation, and archiving. Scand J Public Health 2011; 39: Suppl., 12-16.

9 Frank L. Epidemiology. When an entire country is a cohort. Science 2000; 287: 2398-2399.

10 Pedersen CB. The Danish civil registration system. Scand J Public Health 2011; 39: 7 Suppl., 22-25.

11 Schmidt M, Pedersen L, Sorensen HT. The Danish Civil Registration System as a tool in epidemiology. Eur J Epidemiol 2014; 29: 541-549.

12 Danish Society of Respiratory Medicine. 2017. Danske KOL-Guidelines [Danish COPD Guidelines]. https://www. lungemedicin.dk/fagligt/101-dansk-kol-vejledning-2017.html.

13 Statistics Denmark. Statbank. https://www.dst.dk/en/Statistik/statistikbanken.

14 Christensen AI, Ekholm O, Davidsen M, et al. 2012. The Danish Health and Mobidity Survey 2010. https://www. sdu.dk/sif/-/media/images/sif/udgivelser/2012/sundhed_og_sygelighed_2010.pdf. 
15 Cheng YL, Huang TW, Lin CK, et al. The impact of smoking in primary spontaneous pneumothorax. $J$ Thorac Cardiovasc Surg 2009; 138: 192-195.

16 Jansveld CA, Dijkman JH. Primary spontaneous pneumothorax and smoking. Br Med J 1975; 4: 559-560.

17 Hedevang Olesen W, Katballe N, Sindby JE, et al. Cannabis increased the risk of primary spontaneous pneumothorax in tobacco smokers: a case-control study. Eur J Cardiothorac Surg 2017; 52: 679-685.

18 Bense L, Wiman LG, Hedenstierna G. Onset of symptoms in spontaneous pneumothorax: correlations to physical activity. Eur J Respir Dis 1987; 71: 181-186.

19 Olesen WH, Lindahl-Jacobsen R, Katballe N, et al. Recurrent primary spontaneous pneumothorax is common following chest tube and conservative treatment. World J Surg 2016; 40: 2163-2170.

20 Chambers A, Scarci M. In patients with first-episode primary spontaneous pneumothorax is video-assisted thoracoscopic surgery superior to tube thoracostomy alone in terms of time to resolution of pneumothorax and incidence of recurrence? Interact Cardiovasc Thorac Surg 2009; 9: 1003-1008.

21 Olesen WH, Katballe N, Sindby JE, et al. Surgical treatment versus conventional chest tube drainage in primary spontaneous pneumothorax: a randomized controlled trial. Eur J Cardiothorac Surg 2018; 54: 113-121.

22 Sawada S, Watanabe Y, Moriyama S. Video-assisted thoracoscopic surgery for primary spontaneous pneumothorax: evaluation of indications and long-term outcome compared with conservative treatment and open thoracotomy. Chest 2005; 127: 2226-2230.

23 Hutter J, Reich-Weinberger S, Hitzl W, et al. Sequels 10 years after thoracoscopic procedures for benign disease. Eur J Cardiothorac Surg 2007; 32: 409-411. 